\title{
Research on the Development Trend of Logo Design in the Information Age
}

\author{
Yan Yang \\ Xi’an International University, Shaanxi Xi’an 710077, china
}

Keywords: information age; logo design; development trend

\begin{abstract}
Under the background of social renewal, China has entered the information age. It can be said that the rapid development of information technology has brought great convenience to the social public life and work, and the popularization of information technology has led to significant changes in logo design and art connotation. Because the current public aesthetic ideas undergo important changes in the information age, the traditional logo design for the public cannot meet the needs, logo design in the information age is richer in the characteristics, which is the actual art of extension and content change in the new era. This paper is based on the logo design connotation in information age, and then discusses the important development trend of logo design in the information age.
\end{abstract}

\section{Introduction}

After entering the 21st century, China's science and technology, economy and corresponding culture have all achieved good development. In this kind of big environment background, the logo design shows a significant change trend compared with the past. The change trend can be multidimensional as well as the dynamic and corresponding human nature to sum up, it can be said logo design changes also fully demonstrated the importance of logo design in modern society, as well as the modern public for logo design new development requirements. As the relevant designers need to have a deep understanding of the logo design research, more need to mark the new development trend has a clear understanding, logo design by innovation and then logo design from a single aesthetic liberation of the plight of liberation, the times are more rich in the rich flavour of the times.

\section{On the Connotation of Logo Design}

The sign is essentially a symbol of communication, with a wide range of symbolic meaning, relying on the form of scouring to express a specific meaning, in addition to relying on the public for the symbol association and recognition to promote the expression of the specific meaning of effective communication [1]. And logo design is the use of a variety of means to create a symbol of the actual process, through the creation of different symbols to promote the symbol with artistic value and artistic function. It can be said logo design has long since appeared in ancient times, the ancestors by condensing their wisdom to create a variety of symbols, and this symbol distance has now crossed the four thousand years of history, development has been successfully integrated into modern society logo and modern society Important constituent elements. The modern society to design the logo to be used to highlight the spirit of the times, but rather to shape the brand, transmission of information, etc., logo design can be applied in all aspects of modern life and the development of modern society. Especially after entering the new period, China and other countries around the world formed a close cultural exchange and cooperation, and logo design began in the spirit and the corresponding artistic style or design techniques show a big change, the kind of Logo design new trend also means that China's logo design has entered a new era. 


\section{Analysis on the Important Development Trend of Logo Design in the Information Age}

\subsection{Development of the logo design of multi - dimensional}

With the current development of information technology, digital mapping is becoming more and more mature, many designers began to focus on the development of logo design on top of the expansion of space on the two-dimensional design of the design, For the logo design is no longer limited to the two-dimensional space of artistic expression, but extended to the three-dimensional space and the corresponding four-dimensional space, and even five-dimensional, six-dimensional space above the multi-dimensional space, and relying on the spatial dimension of the extended update It can promote the original planar design to the three-dimensional design of the road of development, of course, based on the multi-dimensional space based on the logo design can also enhance the visual effects, which plays an important role in enhancing the impression of the public logo ]. Such as Sony Ericsson mobile phone logo is built on the basis of three-dimensional design, Ericsson and Sony after the successful merger of the formation of a new Sony Ericsson, Sony Ericsson in order to strengthen the brand in urgent need of a new logo to promote its mobile phone, after many designers The design of the layers of screening after the final establishment of a three-dimensional design based on the mobile phone logo (see Figure 1), and the clever logo Ericsson (English Ericsson) and Sony (English Sony) English initials that " E "and" S ", and the two initials rely on three-dimensional spherical good show, in addition to more practical sphere dealing with the sphere, to promote signs is not just a simple sphere, but with a strong sense of hierarchy, the audience can The sphere of the hierarchical structure to be intuitive view of the whole Sony Ericsson mobile phone logo will also be the inner layer of the ball and the outer texture to distinguish between the inner layer is smooth glazed ball, and the outer matte texture, the first letter "E" and "S" is highlighted in the matte texture of the outer sphere above. It can be said that Sony Ericsson mobile phone of the kind of three-dimensional logo design is the logo design from two-dimensional design to multi-dimensional design of the classic representative works, which is more open logo design to multi-dimensional design of the door. Even in today's Sony Ericsson mobile phone brand of the kind of brand logo is still superior to other brand mobile phone logo. Since then multidimensional logo design continues to emerge, the performance of a variety of colours and various shapes (see Figure II), it can be said that the development of multi-dimensional logo design will greatly meet the community's demand for signs, relying on internal structure and visual illusion or contradiction space Dimensional logo design has already emerged a few years ago, but the logo design of this kind of multi-dimensional space is still an important development trend of present and future logo design, People expect more three-dimensional logo design can be developed to five-dimensional, six-dimensional logo design.

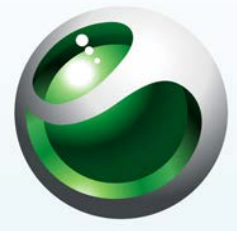

\section{5ony Ericsson}

Figure 1

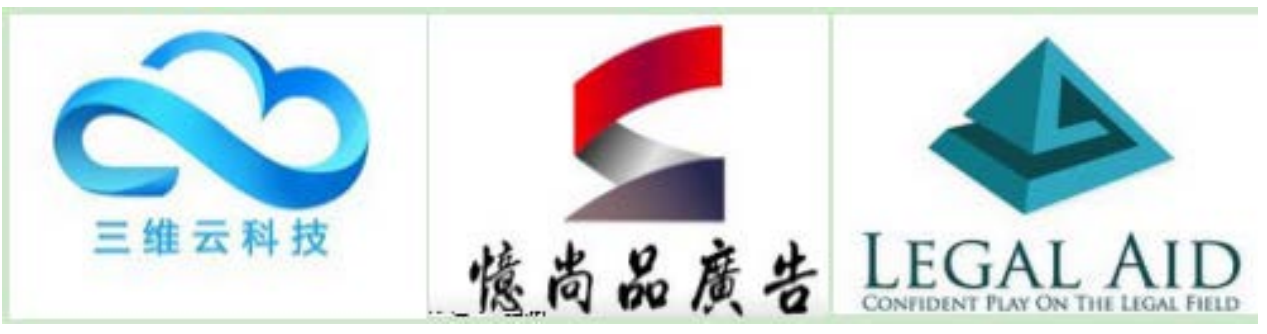

Figure 2 


\subsection{Trend of the logo design dynamic}

Conventionally, the logo design has been used as the main carrier for the boards and the walls, the corresponding paper, and so on, and the design of the logo attached to the above-mentioned carriers can only be given a static effect due to the type of the carrier and the physical attributes presentation [3]. But with the rapid development of information technology, digital technology to lead the trend of the times, showing signs of the traditional carrier is no longer confined to the walls and paper, but extended to the electronic screen, it can be said that the establishment of information technology and digital technology based On the electronic screen has become a symbol of the new carrier of the dissemination of more signs for the design provides a new development ideas to promote the logo design from the previous static presentation into a dynamic presentation. For example, Xiamen Construction Group to design a dynamic signs, the signs are: the first rectangle, then gradually in the rectangle on the corresponding building, and with the building more and more, the original flat rectangular also become More three-dimensional, until the building to the top of the time when the whole rendering of the graphics for the three-dimensional "X" and "J" letters, and these two letters is also the abbreviation of Xiamen Construction Group, Xiamen Construction Group can be said to show the dynamic group Logo design ideas are more novel. Another example is the famous Japanese FM radio station is the design of the dynamic signs, the use of hexagonal form its radio logo that is "EASY851", and the radio logo can also be flexible to change, seven hexagonal free combination, such as Into a two-row structure, a row of letters and another row of numbers; can also become a "v" -type structure, while the letters, while the other side by the digital composition; to the Christmas time of this dynamic radio The logo also incorporates "Merry Christmas" into the shape of the Christmas tree (see Figure 3). While the Japanese FM radio dynamic fun logo design will give the audience left a deep impression, no doubt its radio logo design is more successful. It can be said logo design from the static design into a dynamic design to make signs with vivid and flexible, of course, the meaning of the signs will be more a good expression of diversity, so dynamic is also an important trend of the current logo design trends [4].

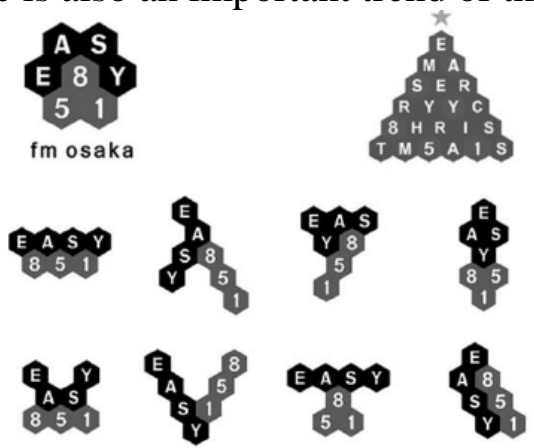

Figure 3

\subsection{Development trend of the logo design of humanity}

Well-known designer Polis has mentioned, "logo design should be based on economic and technical and corresponding aesthetics based on the three, but only concerned about signs of economic and technical or aesthetic is not enough, because the logo design The final target is the people, so it needs to be a good human design which contains ". It is not difficult to see from the prolog's words that the humanized logo design should be the focus of the current designers. Of course, Prolog's words point out that the inner core of the logo design is human nature design. . On the current society, the times change and economic development, material life is more rich, and in this kind of background under the social individual distance is farther and farther, it can be said that most social individuals for ideological communication and emotional exchange are more eager. In addition, logo design is for the social individual and service, and only get a number of social individual identity or recognition can play their design value, but also for the current alienated social interpersonal communication channels or communication, Of the importance of logo design [6]. For example, the well-known brand LG in the brand logo to show a strong humanity, the 
designer will brand letters "L" and "G" for effective integration, which will "G" into a circle, the circle and the human face, "L" is added to "G", and "L" is turned into a nose in a human face. In addition, a point which is cleverly added to a face made of "G" becomes a human face's eye. Thus the entire LG brand logo to become a smiling face, and this sign is a strong affinity, but also by the public favourite (Figure 4) [7]. Another example is the 999 cold spirit is a symbol of the cold spirit of the cup is emitting a heat, and these heat will be together as heart-shaped, combined with slogan "warm very intimate" is the brand can be very user-friendly mark The connotation of the show, as long as the public is suffering from a cold, to see such a brand logo will undoubtedly be a warm heart, and the kind of humanized brand logo with the moment the product and the distance between the public closer. Prompting the product is no longer blunt at the same time cold, but the full integration of public sentiment. As the famous scholar of the original research Zai has said, "The information age is not missing the logo of inspiration, the lack of integration of the emotional vitality of the design" [8]. In general, the logo design as a visual carrier, but which is more able to pass the humanistic care, and the kind of humanistic care can be closer to the distance between the design and social individuals, promote the community to understand the brand value, and humanity is One of the important trends in logo design.

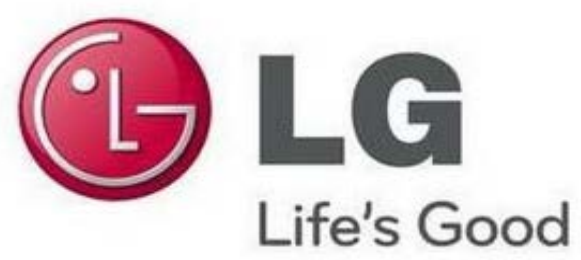

Figure 4

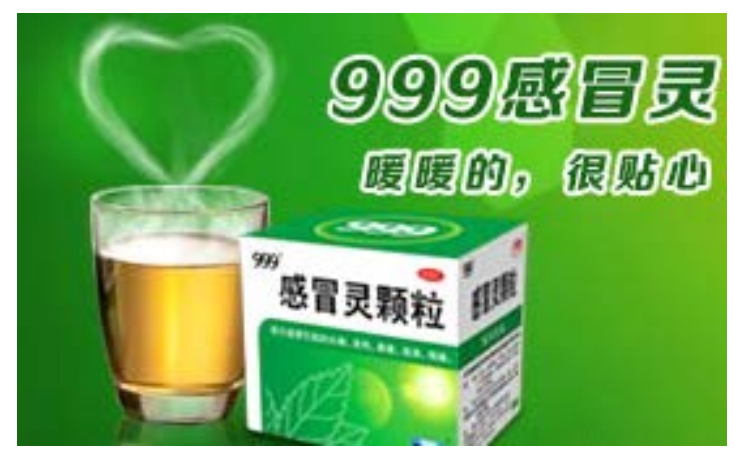

Figure 5

\section{Conclusion}

To sum up, we can see that in today's information age, logo design has become the focus of public attention, and logo design in recent years also show the humanization and multidimensional and corresponding dynamic development trend. In this paper, the logo design under the background of the information age as the core of the study, the expectations for the follow-up on the logo design research to provide theoretical basis for reference, but also designed to mark the future development of optimization give their own research strength.

\section{References}

[1] The Development and Comparison of Marks: A Case Study of the Marks of BP and ExxonMobil [J]. Chunzheng Zhang. Publicities and Literature, 13: 61-62, 2011

[2] From the Rio 2016 Olympic logo to see the development of contemporary sports three-dimensional logo design changes [J]. Airong Duan. Popular Literature, 15: 59-60, 2011

[3] The development trend of office design in the information age --Resolve analysis of office 
environment design [J]. Jiang Zhu. Modern Decoration, 07: 27-28, 2011

[4] Analysis of the new media art under the background of the information design change - a dynamic sign as an example [J]. Zifu Huang, Chunni Zhang. Art and Design (Theory), Z1: 81-83, 2014

[5] Research on the Development Trend of Modern Digital Signage Design Based on Systematic Thinking [J], Jianshe Zhang, Dong Chu. Art Education, 08: 166-168, 2013.

[6] A New Breakthrough in Logo Design in the All Media Era - Reflection on the Principle of Simplicity of Logo Design [J]. Wei Yu, Chaoyang Hu, Kaifeng Gu. Chinese Journal of Advertising, 09: 138-140, 2013

[7] Dynamic Logo Design - On the new media logo design new forms and educational innovation [J]. Cheng Lin, Fu Wang. Design Art Research, 02: 28-33, 2016

[8] Dimension Supplement of VI System - Trend Research on Dynamic Design of Signs [J]. Linfeng Zou. Art \& Tech, 09: 278-279, 2016 